\title{
In Saccharomyces cerevisiae the attenuation of the 2- deoxy-D-glucose toxicity is alleviated by inositol
}

\author{
Chidambaram Ravi ${ }^{1}$, Vasanthi Nachiappan ${ }^{1} *$ \\ ${ }^{1,2}$ Department of Biochemistry, School of Life Sciences, Bharathidasan University, Tiruchirappalli - 620 024, Tamil Nadu, \\ India \\ *Corresponding author: vasanthibch@gmail.com, Mobile: +91 8973721898,
}

Available online at: www.isroset.org

Received: 30/Nov/2018, Accepted: 12/Dec/2018, Online: 31/Dec/2018

\begin{abstract}
In Saccharomysis cerevasiae the glycolytic transcription factor GCR1 tightly controls the expression of genes involved in glycolysis but the importance of Gcr1 transcription in 2-DG toxicity is still elusive. In the present study, we observed 2-DG toxicity in the wild-type, gcr $1 \Delta$, and ino2 $\Delta$ cells under inositol absence (I-) condition obstruct the growth, hence the opil $1 \Delta$ cells were resistant to 2-DG exposure. Further, the presence of 2-DG significantly decreased the promoter activity of INOI in the WT cells. The 2-DG exposure suppressed the growth rate in WT and gcrls strains under inositol limitation condition, but the opils (over production of inositol) strain was resistant to the 2-DG exposure with I- condition. Taken together, the above findings suggest that 2-DG exposure reduced the promoter activity of INOI leads to inositol auxotrophic growth defect, hence the inositol supplementation bring back normal. To conclude that the inositol alleviates the 2DG toxicity in Saccharomyces cerevisiae.
\end{abstract}

Keywords: 2-deoxy-D-glucose, INO1, $\beta$-Galactosidase activity, over production of inositol.

\section{INTRODUCTION}

The transcription factor GCR1 (Glycolytic regulation 1) is an important regulator of glycolytic gene expression in yeast [3] and glycolysis is the primary metabolic pathway used rapidly by yeast for cell proliferation and to ferment glucose to ethanol. In yeast 2-deoxy-D-glucose (2-DG) is an established glucose analogue and the carbohydrate metabolism is altered and leads to defective glycolysis [1, 2]. The 2 DG inhibits growth, affects cell morphology, cell wall biosynthesis and cell lysis [1].

In glycolysis, $H X K$ (hexokinase) activates glucose to glucose-6-phosphate (G-6P), which is used up in the HMP shunt pathway or other metabolic routes including inositol pathway [6, 7]. The hexokinase also phosphorylates 2-DG to 2-DG-6-phosphate (a toxic substance) that cannot be further metabolized $[4,5]$. In the 2-DG treated mice, there is a significant reduction in myo-inositol level. In Saccharomyces cerevisiae the inositol derivatives modulate diverse cellular functions such as apoptosis [12] membrane trafficking [11] and are involved in phospholipid and glycolipid metabolism as well.

The inositol-3-phosphate synthase (INO1) synthesizes inositol-3-phosphate from glucose-6-phosphate [11]. The exposure of 2-DG accumulates 2-DG-6-phosphate and inhibits the formation of myo-inositol phosphate due to the inhibitory effect of 1-L-myo-inositol 1-phosphate synthase [8]. The transcription of INOI was positively controlled by Ino2-Ino4 heterodimer complex, whereas Opi1 is a negative regulator. During the excess availability of inositol, the Opilp is translocated from ER to nucleus where it interacts with $I N O 2$ transcription factor leading to the repression of INOI transcription $[10,13]$.

The 2-DG has been extensively studied and has been revealed to obstruct the metabolic events in various eukaryotic species. In the present study, we examined the importance of exogenous inositol supplementation for alleviating the effect of glucose analogue (2-DG). Additional, we established the importance of INOI promoter activity under various 2-DG concentration in wild-type cells and the behaviour of $O P I 1$ deletion under inositol limitation condition. The current research revealed that the exogenous inositol improves the 2-DG toxicity in yeast.

\section{MATERIALS AND METHODS}

\section{Media and growth condition.}

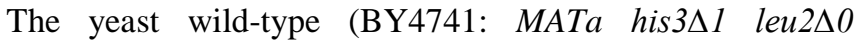
met $15 \Delta 0$ ura $3 \Delta 0$ ) and strains gcr $1 \Delta$, opi $1 \Delta$, and ino $2 \Delta$ were gifted by Prof. Ram Rajasekharan, Central Food Technological Research Institute (CFTRI), Mysore, India. 
Yeast strains was grown in YPD (1\% in yeast extract, $2 \%$ peptone, and $2 \%$ dextrose) medium $(\mathrm{pH} 7.0)$ or synthetic complete (SC) / defined (SD) media containing yeast nitrogenous base $0.67 \mathrm{~g}$ (YNB), yeast dropout with respective amino acids $(0.14 \mathrm{~g}$ uracil $7.6 \mathrm{mg}$, tryptophan 7.6 $\mathrm{mg}$, leucine $38 \mathrm{mg}$, and histidine $7.6 \mathrm{mg}$ ) and $100 \mathrm{mg} / \mathrm{L}$ kanamycin with aeration at $30{ }^{\circ} \mathrm{C}$ at $180 \mathrm{rpm}$ for $24 \mathrm{~h}$. The cell growth was monitored by measuring the absorbance at $600 \mathrm{~nm}$. The YEp357R vector containing INO1-LacZ was gifted from John M. Lopes, College of Natural Sciences, University of Massachusetts, Amherst, MA. The yeast INO1-LacZ containing YEp357R vector was used for promoter reporter studies. Cells were grown until mid-log phase in $5 \mathrm{~mL}$ of synthetic defined uracil (SD-Ura) containing $2 \%$ glucose. The cells were pelleted and resuspended with fresh SD-Ura medium in the presence (I+) or absence $(\mathrm{I}-)$ of inositol $(75 \mu \mathrm{M})$ and the cells were continued shaking with $180 \mathrm{rpm}$ at $30{ }^{\circ} \mathrm{C}$. The E. coli transformants was selected on LBA plates containing $0.5 \%$ yeast extract, $1 \%$ peptone, $1 \% \mathrm{NaCl}$, and $100 \mathrm{mg} / \mathrm{L}$ ampicillin.

\section{Cell tolerance assessment of 2-Deoxyglucose resistance by spot test assays.}

The overnight culture of WT, gcrl $\Delta$, opi $1 \Delta$ and ino $2 \Delta$ cells were grown in YPD media at $30{ }^{\circ} \mathrm{C}$. The cells were normalized by $\mathrm{OD}\left(\mathrm{A}_{600 \mathrm{~nm}}\right)$ and equal number of cells were serially diluted (10-fold) with autoclaved double distilled water, and $3 \mu \mathrm{l}$ aliquots of each dilution were spotted onto $\mathrm{SC}$ and the media containing either presence or absence of inositol with and without exposure of $0.025 \%$ and $0.050 \%$ of $2-\mathrm{DG}$ and $2 \%$ dextrose as a carbon source containing agar plates and incubated $30^{\circ} \mathrm{C}$ for 3 days.

\section{B-Galactosidase activity of INO-LacZ assay}

The wild-type strains were transformed with YEp357INOI-LacZ fusion gene containing plasmid and single colony transformants were grown in synthetic defined uracil (SD-Ura) media up to mid-log phase at $30{ }^{\circ} \mathrm{C}$. The cells were then washed with fresh SD-Ura media and subcultured in SD-Ura media with or without inositol (I- or I+), and in the presence or absence of $2-\mathrm{DG}(0.025 \%$ and $0.050 \%$ ) and incubated at $30{ }^{\circ} \mathrm{C}$ for $4 \mathrm{~h}$. The cell free extract was collected, protein extracted and quantified by Bradford method [19]. The $\beta$-Galactosidase activity was measured as described previously by Rose and Botstein [20]. The INOI$\mathrm{LacZ}$ activity was expressed as nmol. $\mathrm{min}^{-1}$. $\mathrm{mg}^{-1}$ protein.

\section{Statistical analysis}

The experimental data quantification was analyzed using Student's t-test, and the obtained difference was considered statistically significant $* \mathrm{p}<0.05$. At least three independent experiments were repeated andata are presented as the average \pm standard deviation (SD). Statistical analysis was performed using the sigma plot 10.0 software.

\section{RESULTS AND DISCUSSION}

Effect of 2- DG on the growth of WT, gcr1 $\Delta$, opi1 $\Delta$, and ino2 $\Delta$.

Exposure of cells to 2-DG (highly toxic compound) resulted in growth inhibition, and this might be due to the altered metabolism mainly the glycolysis and HMP shunt pathway (16). In the present study, we examined the effect of 2-DG (glucose analogue) during the deletion of transcription factors in glucose $(\mathrm{gcrl})$ and lipid metabolism (opils, ino2 $\Delta$ ). To study the growth, we used spot assay using the synthetic completed media contains $2 \%$ glucose (SC-D)) in the presence and absence of $0.025 \%$ and $0.050 \%$ DG. The exposure of $0.05 \%$ 2-DG caused a significant inhibition with cell growth in WT, gcr $1 \Delta$, ino $2 \Delta$ cells, but still the growth of opi $1 \Delta$ cells slightly increased compared to WT cells (Fig. 1). Previous results revealed that over expression of $G C R 1$ suppressed the 2-DG toxicity mildly in glucose containing media [18]. The gcrl $\Delta$ cells were highly sensitive to $0.05 \%$ 2-DG (Fig.1) and confirmed that 2-DG inhibited the yeast cell growth under fermentation condition.

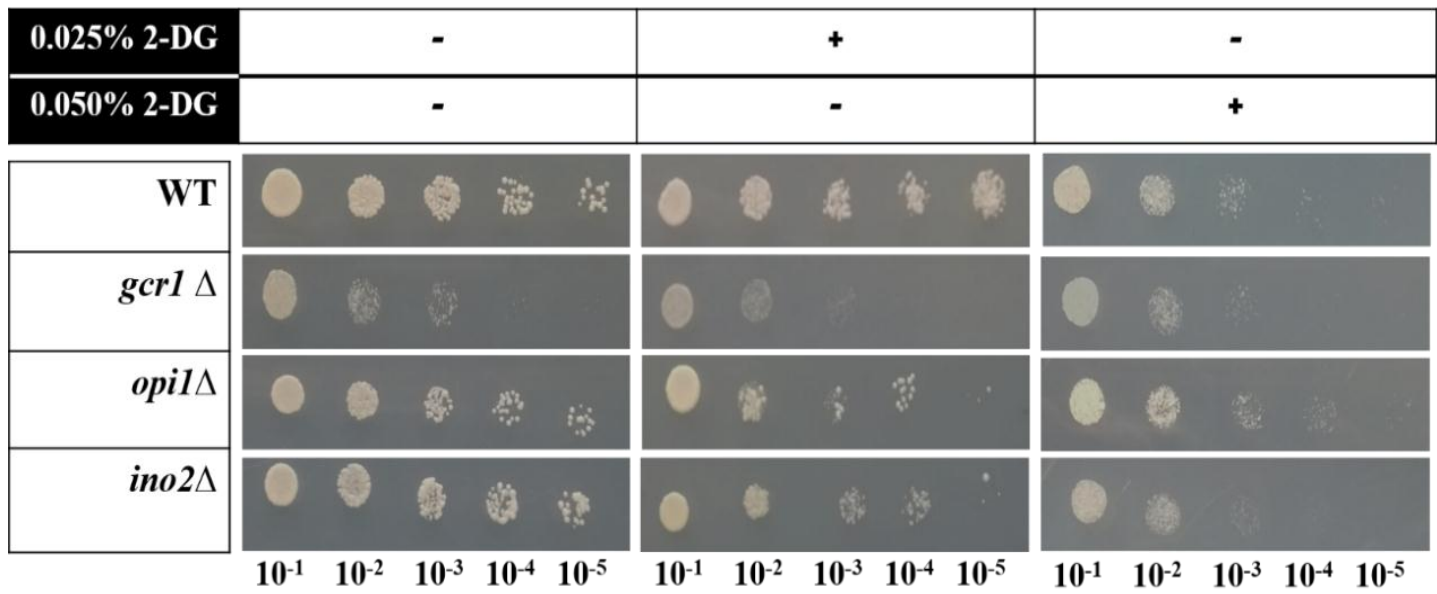

Fig.1. Cell tolerance assessment of 2-DG in control and deletion strains 
The WT and deletion strains were cultured in YPD media and grown up to mid-log phase at $30{ }^{\circ} \mathrm{C}$. The cells were serially diluted (10- fold), and $3 \mu$ l of cells were spotted onto SC $2 \%$ dextrose agar plates in the presence or absence of 2DG $(0.025 \%$ and $0.050 \%)$ and incubated for 3 days at $30{ }^{\circ} \mathrm{C}$.

\section{Effect of 2-DG in INO1 lacZ activity in WT cells.}

The presence of 2-DG accumulates 2-DG-phosphate (toxic) which causes an inhibitory effect on myo-inositol-1phosphate formation [8]. In yeast the inositol-3-phosphate synthase (INO1) synthesizes inositol-3-phosphate from glucose-6-phosphate [11]. We analyzed the promoter activity of INOI gene using $\beta$-galactosidase assay. In the wild-type cells with $0.025 \%$ and $0.050 \%$ 2-DG exposure $\sim 35 \%$ and $\sim 60 \%$ reduction were observed respectively when compared to the control (WT untreated) cells (Fig.2). We performed the promoter reporter assay of INOI-LacZ activity and the data confirms that $2-\mathrm{DG}$ is a toxic to the cells and affected the INOI $\beta$-galactosidase activity.

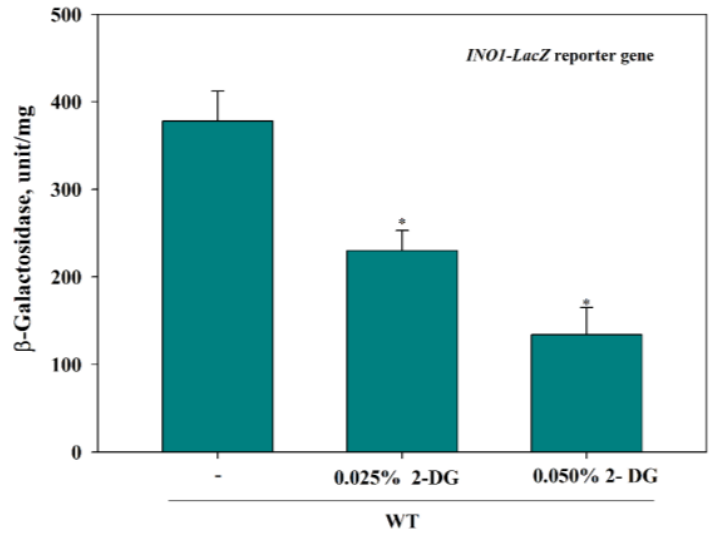

Fig.2. $\beta$-Galactosidase activity of INO1-LacZ in WT cells under 2- DG exposure

The WT cells harbouring YEp357R plasmid containing INO1-LacZ fusion gene was cultured in SD-Ura media up to mid $\log$ phase with or without 2 -DG $(0.025 \%$ and $0.050 \%)$ and the $\beta$-Galactosidase activity was measured in the cell extract. The $\beta$-Galactosidase specific activity was expressed as units mg-1 (nmol min-1 mg-1) incomplete. The data shows the average of three independent experiments $(* \mathrm{P}<$ $0.05)$.

Effect of 2- DG on $\beta$-Galactosidase activity of INO1-LacZ in WT cells in the presence or absence of inositol.

We also performed the promoter reporter assay of INOI$L a c Z$ activity in different combination of 2-DG in the presence (I+) or absence (I-) of inositol. The INOI expression is highly expressed under inositol limitation condition $[10,11]$, and we also found increased INO1-LacZ activity under $\mathrm{I}-$ condition in WT cells compared to I+ (Fig.3). The $\beta$-Galactosidase activity of WT cells was substantially lower with the presence of $0.025 \% 2-\mathrm{DG}$ and was further reduced with $0.050 \%$ 2-DG in the WT cells with inositol presence when compared to WT cells under Icondition (Fig.3) and the comparable reduction was observed in WT I+ during $0.02 \%$ and $0.05 \% 2-\mathrm{DG}$ exposure also (Fig.3). These results suggest that the inositol auxotrophy condition with the WT cells were highly sensitive to the exposure of 2-DG and reduced the INOI transcription in yeast cells.

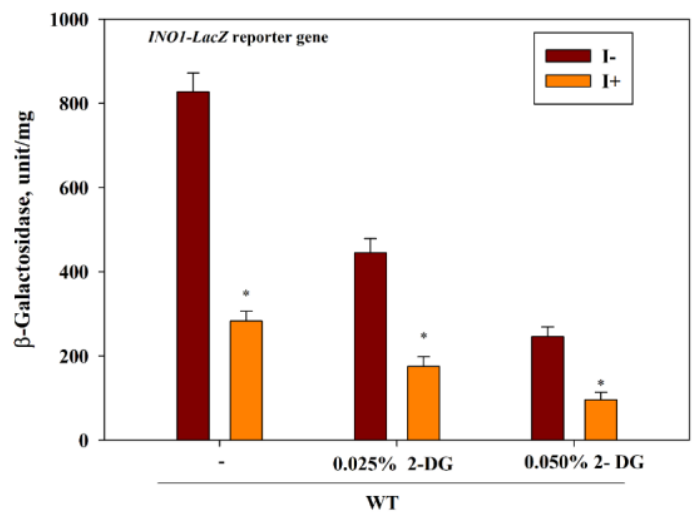

Fig.3. $\beta$-Galactosidase activity of INO1- $\mathrm{LacZ}$ in WT cells

The WT cells containing INO1-LacZ fusion gene transformants were allowed to grow up to mid-log phase in SD-Ura media at $30^{\circ} \mathrm{C}$. The cells were then collected and washed with fresh SD-Ura I- media and resuspended with fresh SD-Ura I- and SD-Ura I+ media containing $0.025 \%$ and $0.050 \%$ 2-DG and allowed to grow for $4 \mathrm{~h}$. The cells were collected and the $\beta$-Galactosidase activity measured in the cell extract. The specific $\beta$-Galactosidase activity was expressed as units mg-1 (nmol min-1 mg-1). The data shown is average of three independent experiments $(* \mathrm{P}<0.05)$.

Spot test analysis of WT, gcr $1 \Delta$, opi1 $\Delta$, and ino $2 \Delta$ cells in the presence or absence of inositol under exposure of 2 DG

The $O P I 1$ is a negative regulator of lipid metabolism, hence the opil$\Delta$ cells showed an increase in growth under Icondition compared to WT cells [10]. Normally the lack Opi1 (indicator of over production of inositol), increases the growth under inositol limitation compared to control cells (Fig.4). The growth pattern was measured in the WT and deletion strains during the 2-DG exposure under I- and I+ condition. The gcrl $\Delta$ highly repressed the growth with $0.025 \%$ and $0.050 \%$ 2-DG under inositol limitation condition. The 2 DG exposure reduced the growth and was retrieved with inositol $(75 \mu \mathrm{M})$ compared to WT cells without inositol (Fig.4). Normally the lack of INO2 requires exogenous inositol for growth, and the deletion displays an inositol auxotrophy [10]. As a result, the growth was fully abolished with ino2 $\Delta$ cells under 2-DG exposure with Icondition compared to I+. 
A.

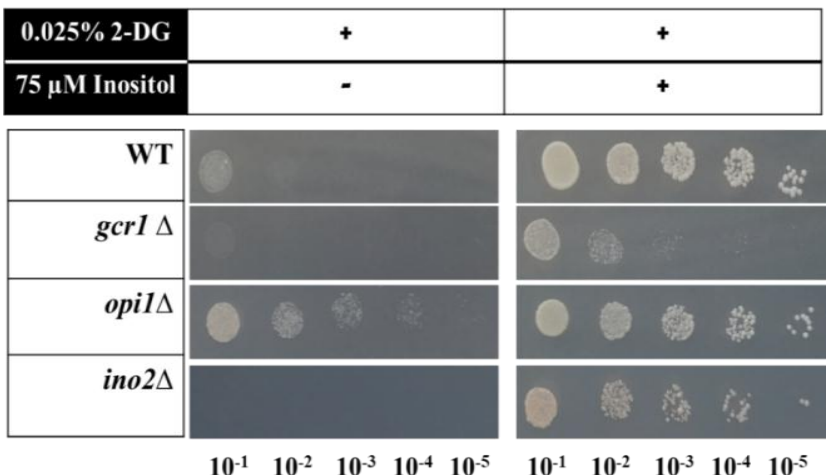

B.

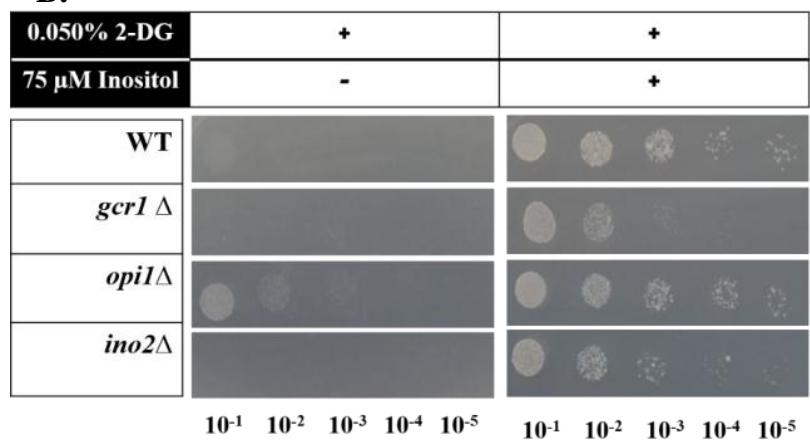

Fig.4. Growth study

The WT, gcr $1 \Delta$, opi $1 \Delta$, and ino2 $\Delta$ cells were cultured in YPD media and grown up to mid-log phase at $30{ }^{\circ} \mathrm{C}$. The cells were then serially diluted (10- fold), and $3 \mu \mathrm{l}$ of cells were spotted onto agar plates with $\mathrm{SC} \mathrm{I}^{-}$and $\mathrm{SC} \mathrm{I}+$ containing $2 \%$ dextrose with the presence or absence of 2DG $(0.025 \%$ and $0.050 \%)$ and incubated for 3 days at $30{ }^{\circ} \mathrm{C}$.

The growth of the opild cells was more in the presence of 2DG $(0.025 \%$ or $0.050 \%)$ with I- condition compared to WT I- cells (Fig.4), implying the cells were resistant to 2-DG and growth was not affected in opil $\Delta$ cells compared to the WT cells under I- condition.

\section{CONCLUSION.}

The WT yeast cells were highly sensitive to the toxic compound 2 DG and the growth inhibited in I- condition. However, the growth was not inhibited with opild cells and was able to tolerate the 2 DG toxicity $(0.025 \%$ and $0.050 \%)$ in I- condition. Our study, we conclude that the inositol is essential to alleviate the 2-DG toxicity in Saccharomyces cerevisiae. Further work is needed to study the molecular mechanism and the phenotypic importance of $O P I 1$ in 2-DG toxicity under inositol auxotrophic condition.

\section{ACKNOWLEDGMENT}

We are thankful to DST-SERB Grant No: EMR/2016/001727, New Delhi under EMR scheme. We are grateful to Prof. Ram Rajasekharan (Central Food Technological Research Institute, Mysore, India) for providing yeast strains, over expression plasmids, reagents and instrument facility. We also thank Prof. John M. Lopes (College of Natural Sciences, University of Massachusetts, Amherst, MA) for giving the YEp357R-INO1-LacZ plasmid.

\section{REFERENCE}

[1]. P. Biely, Z. Kratky, J. Kovařík, Š. Bauer, "Effect of 2Deoxyglucose on cell wall formation in Saccharomyces cerevisiae and its relation to cell growth inhibition", J Bacteriol, Vol.107, Issue.1, pp 121-129, 1971.

[2]. Z. Kratky, P. Biely, S. Bauer, "Mechanism of 2-Deoxy-d-glucose inhibition of cell-wall polysaccharide and glycoprotein biosynthesis in Saccharomyces cerevisiae”, Eur J Biochem, Vol.54, Issue.2, pp 459-67, 1975.

[3]. K.A. Willis, K.E. Barbara, B.B. Meno, J. MoVat , B. Andrews, G.M. Santangelo, "The global transcriptional activator of Saccharomyces cerevisiae, Gcrlp, mediates the response to glucose by stimulating protein synthesis and CLN-dependent cell cycle progression", Genetics Vol.165, Issue.3, pp 1017-1029, 2003.

[4]. H.T.A. Jaspers, J. van Steveninck, "Transport-associated phosphorylation of 2-deoxy-d-glucose in Saccharomyces fragilis", BBA Biomembranes, Vol.406, Issue.3, pp 370-85, 1975.

[5]. Z. Lobo, P.K. Maitra, "Resistance to 2-deoxyglucose in yeast: a direct selection of mutants lacking glucose-phosphorylating enzymes", Mol Gen Genet, Vol.157, Issue.3, pp 297-300, 1977.

[6]. A.N. Wick, D.R. Drury, H.I. Nakada, J.B. Wolfe, "Localization of the primary metabolic block produced by 2-deoxyglucose”, J Biol Chem, Vol.224, Issue.2, pp 963-969, 1957.

[7]. W. Chen, M. Gueron, "The inhibition of bovine heart hexokinase by 2-deoxy-Dglucose-6-phosphate: Characterization by $31 P$ NMR and metabolic implications", Biochimie, Vol. 74, Issue.9-10, pp 867-873, 1992.

[8]. L.E. Burton, W.W. Wells, "Studies on the effect of 5-thio-d-glucose and 2-deoxy-d-glucose on myo-inositol metabolism", Archives of Biochemistry and Biophysics, Vol.181, Issue.2, pp 384-392, 1977.

[9]. J.I. Nikawa, T. Nagumo, S. Yamashita, "myo-Inositol Transport in Saccharomyces cerevisiae”, Journal of Bacteriology, Vol.150, Issue. 2 , pp 441-446, 1982.

[10]. G.M. Carman and G.S. Han, "Regulation of phospholipid synthesis in the yeast Saccharomyces cerevisiae”, Annu. Rev. Biochem, Vol.80, pp 859-883, 2011.

[11]. S.A. Henry, S.D. Kohlwein and G.M. Carman, "Metabolism and regulation of glycerolipids in the yeast Saccharomyces cerevisiae", Genetics. Vol.190, Issue.2, pp 317-349, 2013.

[12]. J.D. York, S. Guo, A.R. Odom, B.D. Spiegelberg and L.E. Stolz, "An expanded view of inositol signalling", Adv. Enzyme Regul, Vol.41, pp 57-71, 2001.

[13]. N. Bachhawat, Q. Ouyang and S.A. Henry, "Functional characterization of an inositol-sensitive upstream activation sequence in yeast. A cis-regulatory element responsible for inositol choline-mediated regulation of phospholipid biosynthesis", J. Biol. Chem, Vol.270, Issue.42, pp 25087-25095,1995. 
[14]. J.R. Gibbins, "Epithelial cell motility: The effect of 2-deoxyglucose on cell migration, ATP production, and the structure of the cytoplasmic ground substance in lamellipodia of epithelial cells in culture”, Cell Motil, Vol.2, Issue.1, pp 25-46, 1982.

[15]. H.T. Kang, E.S. Hwang, "2-Deoxyglucose: An anticancer and antiviral therapeutic, but not anymore a low glucose mimetic", Life Sci, Vol.78, Issue.12, pp 1392-1399, 2006.

[16]. M. Ralser, M.M. Wamelink, E.A. Struys, C. Joppich, S. Krobitsch, C. Jakobs, H. Lehrach, "A catabolic block does not sufficiently explain how 2-deoxy-D-glucose inhibits cell growth", Proc Natl Acad Sci U S A, Vol.105, Issue.46, pp 17807-11, 2008.

[17]. R.R. McCartney, D.G. Chandrashekarappa, B.B. Zhang, and M.C. Schmidt, "Genetic Analysis of Resistance and Sensitivity to 2Deoxyglucose in Saccharomyces cerevisiae", Genetics, Vol.198, Issue.2, pp 635-646, 2014.

[18]. P.A. Gibney, A. Schieler, J.C. Chen, J.M. Bacha-Hummel, M. Botstein, M. Volpe, S.J. Silverman, Y. Xu, B.D. Bennett, J.D. Rabinowitz, D. Botstein, "Common and divergent features of galactose-1-phosphate and fructose-1-phosphate toxicity in yeast", Mol Biol Cell, Vol.29, Issue.8, pp 897-910, 2018.

[19]. M.M. Bradford, "A rapid and sensitive method for the quantitation of microgram quantities of protein utilizing the principle of proteindye binding", Anal. Biochem, Vol.72, Issue.1-2, pp 248-254, 1976.

[20]. M. Rose and D. Botstein, "Construction and use of gene fusions to lacZ ( $\beta$ - galactosidase) that are expressed in yeast", Methods Enzymol, Vol.101, pp 167-180, 1983. 